\title{
EDUCAÇÃO PÚBLICA E INDEPENDÊNCIAS NA AMÉRICA ESPANHOLA E BRASIL: EXPERIÊNCIAS LANCASTERIANAS NO SÉCULO XIX
}

\author{
María Helena Camara Bastos ${ }^{1}$ \\ Pontifícia Universidade Católica do Río Grande do Sul-Brasil \\ mbbastos@pucrs.br
}

Recepción: 05/04/2011

Evaluación: 11/07/2011

Aceptación: 29/05/2012

Artículo de Revisión

doi: 10,9757

\section{RESUMO}

A difusão do método lancasteriano ou monitorial/mútuo está intimamente ligada à necessidade de extensão da educação a todas as classes sociais, luta empreendida pelo iluminismo e colocada em prática, ao menos no papel, nos nascentes sistemas educativos públicos do século XIX. Após o processo de independência das colônias de Espanha e Portugal, a questão da educação elementar foi um dos problemas a ser resolvido nas emergentes repúblicas. O método de Bell e Lancaster foi adotado em vários países: Cuba, Porto Rico, Guatemala, México, Uruguai, Argentina, Chile, Perú, Brasil, Colômbia, Venezuela, Equador, Paraguai. Em 1818, Joseph Lancaster, a convite de Simon Bolivar, realizou viagem à América do Sul, onde divulgou seu método e estabeleceu escolas. Posteriormente, também empreendeu viagem aos Estados Unidos e Canadá. O presente estudo analisa a difusão e implementação do ensino mútuo/monitorial em alguns países, focando a experiência brasileira e enfatizando sua contribuição para o desenvolvimento e generalização do ensino elementar. A adoção do método nas Américas esteve afinada com o movimento de internacionalização de saberes pedagógico e modelos educativos, na primeira metade do século XIX.

Palavras-chave: Revista História da Educação Latino-americana, instrução, pública, método lancasteriano, independências, século XIX.

Professora do Programa de Pós-gradução em Educação da Pontifícia Universidade Católica do Río Grande do Sul. Doutora em História e Filosofia da Educação; Pós-doutora no Service d'histoire de l'éducation-INRP/França. Av. Ipiranga 6681. CEP: 90.619-900 Porto Alegre/RS - Brasil. 


\section{PUBLIC EDUCATION AND INDEPENDENCE \\ IN SPANISH AMERICA AND BRAZIL: LANCASTERIANAS EXPERIENCES IN THE NINETEENTH CENTURY}

\begin{abstract}
Monitoring or Lancaster's method and its wide spread are very attached to the need of educating through all social classes, illustration movement battle and becoming practical at least in the role of making public education systems of 19th century more practical. Elementary school education became an issue in the new nations after the independece process of Spanish and Portuguese colonies. Bell and Lancaster's method was adopted in several countries such as: Cuba, Puerto Rico, Guatemala, México, Uruguay, Argentina, Chile, Perú, Bolivia, Brasil, Colombia, Venezuela, Ecuador, Paraguay. Joseph Lancaster came in different ocations to south America as invited by Simon Bolivar, Lancaster launched his method and created shools in these jurneys. He also promised travelling to the US and Canada.
\end{abstract}

This paper analyses spread and implementation of mutual or monitorial teaching methods focusing in some countries. Studying Brasilean approach and experience, highlinting on contribution to elementary education development and spread. Adoption of Americas' Method which was tuned with educational knowledge and models international processes in the first half of 19th Century.

Key words: Journal of Latin American Education History, public education, lancasterian method, independence, the nineteenth century.

\section{EDUCACIÓN PÚBLICA E INDEPENDENCIAS \\ EN LAS AMERICAS ESPAÑOLAS \\ Y BRASIL: EXPERIENCIAS LANCASTERIANAS EN EL SIGLO XIX}

\section{RESUMEN}

La difusión del método lancasteriano o monitoral/mutuo está estrechamente vinculada a la necesidad de extender la educación a todas las clases sociales, la lucha de la Ilustración y poner en práctica, al menos sobre el papel, los sistemas de educación pública del siglo XIX. Después del proceso de independencia de las colonias de España y Portugal, la cuestión de la educación primaria fue uno de los problemas a resolver en las repúblicas emergentes. El método de Bell y Lancaster se adoptaron en varios países: Cuba, Puerto Rico, Guatemala, México, Uruguay, Argentina, Chile, Perú, Bolivia, Brasil, Colombia, Venezuela, Ecuador, Paraguay. En 1818, Joseph Lancaster, por invitación de Simón Bolívar, hizo viajes a América del Sur, donde dio a conocer su método y las escuelas creadas. Más tarde, también se comprometió viajar a los Estados Unidos y Canadá. Este estudio analiza la difusión e implementación de la enseñanza mutua/ monitorial en algunos países, centrándose en la experiencia brasileña, haciendo hincapié en su contribución al desarrollo y la generalización de la educación primaria. La adopción del método en las Américas estaba en sintonía con el proceso de internacionalización del conocimiento educativo y los modelos educativos en la primera mitad del siglo XIX.

Palabras clave: Revista Historia de la Educación Latinoamericana, educación pública, método lancasteriano, independencias, siglo XIX.

\section{INTRODUÇÃO}

A difusão do método lancasteriano ou monitorial/mútuo está intimamente ligada à necessidade de extensão da educação a todas as classes sociais, luta empreendida pelo iluminismo e colocada em prática, ao menos no papel, nos nascentes sistemas educativos públicos do século XIX².

Vincent afirma que o ensino mútuo nasce com o processo de industrialização, com a função de transmitir rapidamente, com poucos gastos

2 María Isabel Cortis Giner y María Consolación Calderón España. El método de enseñanza mutua. Su difusión en la América Colonial Española. História da Educação v. XIV-XV (1995-96): 279-300. 
a todos os alunos, os saberes e o saber-fazer indispensável àquele momento histórico. É uma etapa da história da instrução pública e das escolas de primeiras letras, como parte do processo de incorporação das modernidades dos países centrais, em fase de industrialização e conseqüente formação de cidadãos adaptados a essa realidade. A difusão da instrução elementar às massas trabalhadoras exigia a racionalização do ato pedagógico - pela rapidez em ensinar, pelo baixo custo, pela disciplina e ordem, pelo uso de poucos professores e vários alunos-mestres ${ }^{3}$.

Na América espanhola e no Brasil, após o processo de independência das colônias de Espanha e Portugal ${ }^{4}$, a questão da educação elementar foi um dos problemas a ser resolvido. O método de Bell e Lancaster foi adotado em vários países: Cuba, Porto Rico, Guatemala, México, Uruguai, Argentina, Chile, Peru, Brasil, Colômbia, Venezuela, Equador, Bolívia ${ }^{5}$, Paraguai ${ }^{6}$. Em 1818, Joseph Lancaster, a convite de Simon Bolívar, realizou viagem à América do Sul, onde divulgou seu método e estabeleceu escolas. Posteriormente, também empreendeu viagem aos Estados Unidos e Canadá.

O presente estudo aborda a história do ensino monitorial/mútuo, analisa a difusão e adoção oficial em alguns países da América espanhola, focando a experiência brasileira, e enfatiza sua contribuição para o desenvolvimento e generalização do ensino elementar.

\section{Um pouco da história do ensino monitorial/mútuo}

Nos últimos anos do século XVIII, vemos surgir um novo método de ensino: monitoral ou mútuo. Até então, os professores de primeiras letras adotavam o ensino individual e/ou o simultâneo, nos quais o agente de ensino é o professor. No método monitorial/mútuo, a responsabilidade é dividida entre o professor e os monitores, visando a uma democratização das funções de ensinar ${ }^{7}$.

Guy Vincent, L'école primaire franşaise. Etude sociologique (Lyon: PuLyon, 1980), 261.

Argentina (1810); Bolívia (1809-1825); Brasil (1822); Chile (1810-1826); Colômbia (1819); Cuba (1898); Equador (1822/1830); Guatemala (1821); (México (1810); Paraguai (1811); Perú (1821); Uruguai (1828); Venezuela (1821/1830), Cuba (1895), Porto Rico (1898).

5 A Bolívia também adota o ensino mútuo pela lei de 9 de fevereiro de 1827. Esse método de ensino foi adotado somente para um grupo de privilegiados.

6 Sobre o Paraguai, ver Heinz Peters, El sistema educativo paraguayo desde 1811 hastas 1865. (Paraguay: Instituto Cultural Paraguayo-Alemán, 1996).

Sobre a pedagogía do ensino mútuo, ver Anne Querrien. L'école mutuelle, une pédagogie trop efficace? (Paris: Empencheur de Penser en Rond, 2005). 
Zélis, ao traçar a história do ensino mútuo, afirma que um esboço do mesmo é encontrado nas escolas monásticas, nas escolas dos Irmãos de Vida Comum, na Alta Idade Média, e em certas escolas de caridade, no período anterior à Revolução Francesa ${ }^{8}$. Libercourt assinala também que Comenius havia preconizado esse método por permitir ensinar tudo a todos ${ }^{9}$. O método, no entanto, seria sistematizado separadamente por André Bell (1753-1832) e por Joseph Lancaster (1778-1838), que reivindicam a paternidade do mesmo.

Bell, médico e pastor anglicano, aplica princípios do método nas Índias Inglesas, em Madras, onde dirigiu um orfanato de 1787 a 1794. Não podendo contar com mestres capacitados, teve a idéia de utilizar os melhores alunos - os monitores - para transmitir aos demais os conhecimentos que haviam aprendido com o professor, o que permiti instruir mais de duas centenas de alunos. Quando retorna à Inglaterra, publica Essai d'éducation fait au collège de Madras (1797), em que relata sua experiência: "o meio pelo qual uma escola inteira pode instruir-se ela mesma sob a supervisão de um só professor".

Ao mesmo tempo, Lancaster, da seita dos Quackers, cria uma escola para crianças pobres em Londres (oitocentos meninos e trezentas meninas), em 1798. Diante do problema de instruir gratuitamente grande número de alunos sem utilizar muitos professores decidi dividir a escola em várias classes, colocando em cada classe como monitor um aluno, com conhecimento superior ao dos outros e sob direção imediata do professor. Percebe que, por esse método, um só professor era suficiente para dirigir, com ordem e facilidade, uma escola de quinhentos e até mil alunos. Publica, em 1803, a obra Improvements in education at it respectsy he industrious classes of the comunity, em que destaca os resultados obtidos, estimulando a abertura de inúmeras escolas adotando o método lancasteriano. Com alguns nobres, organiza a Royal Lancastrian Society, a qual permite a ampla divulgação do método e de seus materiais didáticos.

O método lancasteriano baseia-se no ensino dos alunos por eles mesmos, divididos em várias classes, seis em geral, todos com nível de conhecimento semelhante, ou seja, nenhum aluno sabe nem mais nem menos que o outro. O aluno é integrado a uma classe, depois de averiguado seu conhecimento. A classe tem um ritmo determinado de estudo e um programa a desenvolver de leitura, escrita e aritmética. Cada aluno pode pertencer, ao mesmo tempo, a várias classes diferentes: pode estar mais avançado em leitura do que na

Guy Zélis, L'École Primaire en Belgique, depuis Moyen Âge. (Belgique: Galerie GGER, 1986-87), 133. Alexandre Librecourt, Bell e Lancaster. Promoteurs de l'enseignement mutuel. Revue Education Enfantine: No. 985 (dec. 1996). 
escrita ou no cálculo. Cada classe é dirigida por um instrutor, o monitor, principal agente do método. É um dos alunos da classe que, dentro de uma especialidade determinada, se distingue pelos seus resultados e é colocado à testa da classe. O professor, antes do início da aula, dá uma explicação especial e indicações particulares. O monitor é que tem o controle da classe e que classifica os alunos na classe. Quando um aluno se distingue, quando se mantém regularmente como primeiro da classe, pode ascender à classe superior, ocupando o último lugar. Se, depois de algum tempo, não for observado progresso, ele retorna à classe que estava. Ele também pode ajudar o monitor e, no caso de sua ausência ou na sua promoção, substituí-lo. Assim, durante o ano, ocorre um movimento contínuo de classificação dos alunos.

Com essa organização, o papel do professor é restrito, não tem contato direto com os alunos, a não ser antes da aula com os monitores. Durante a aula, permanece em sua mesa, a frente da sala, sob um estrado, assistido por um ou dois monitores, os mais velhos e instruídos, que transmitem suas ordens e o substituem em caso de falta. Como chefe de orquestra, regula a marcha da escola. Para conduzir e avaliar corretamente as centenas de alunos, o professor emite ordens precisas e de fácil compreensão, através de sineta, apito ou de um bastão. Além disso, controla o movimento dos alunos: a entrada, a saída, a instalação nos bancos, as mudanças de exercício; controla e regulariza o trabalho dos monitores e, se um deles demonstrar pouco zelo na função, o coloca na classe superior e designa um sucessor; inversamente, se percebe que um monitor abusa do poder, o repreende. O telégrafo assegura a comunicação entre o professor, o monitor geral e os demais monitores.

Na escola mútua, o tempo é rigidamente disciplinado. A seqüência das atividades e os comandos necessários à sua execução são meticulosamente previstos e descritos nos guias, manuais, tratados publicados para os professores. O programa de ensino compreende, para os meninos, a leitura, a escrita e o cálculo; para as meninas, além dessas disciplinas, a costura. Cada matéria ensinada repousa sob um programa preciso e detalhado, que se encontra nos guias e tratados elaborados por Nyon, Bally, Sarazin e outros. Cada programa é dividido em oito graus hierarquizados, que devem ser percorridos sucessivamente. Os ritmos de aprendizagem e de aquisição de conhecimento variam de acordo com o aluno e a disciplina. O método faz uso de técnicas e materiais diversos em sala de aula; recorre constantemente a quadros e tabelas ilustradas, os silabários, aos quadros de leitura e de cálculo; ao quadro-negro, à ardósia, à formação de letras na terra com o dedo ${ }^{10}$.

10 Pierre Lesage, La pedagogie dans les écoles mutuelles au XIX siècle. Revne Française de Pédagogie: No. 31 (abril-mai-juin 1975), 62-69. 
O entusiasmo pelo método reside na facilidade de manter a disciplina. Uma hierarquia de recompensas estimula o trabalho dos alunos. A satisfação pessoal é estimulada pelo progresso rápido, de classe em classe, ou pela possibilidade de tornar-se monitor, ou pela distribuição de prêmios - jogos, livros - ou de dinheiro, isto é, os monitores recebem um pequeno pagamento. Enfim, aqueles que se destacam durante seus estudos recebem um certificado, que facilita sua colocação profissional. As sanções aos alunos são em ordem crescente, de acordo com a infração: ficar em quarentena num banco particular; em isolamento num gabinete especial, durante a aula; em solitária; permanecer na classe após o final dos exercícios; permanecer em frente de um cartaz, onde estão listadas as faltas cometidas, enfim, a expulsão da escola. As sanções mais graves, que fugiam ao controle do monitor, e mesmo do professor, são registradas no livro negro. As sanções são determinadas por um júri, constituído pelos próprios alunos que avaliam os seus pares, como num verdadeiro processo.

A principal vantagem destacada do método é de ordem econômica, por permitir que um professor ensine em pouco tempo grande número de alunos. Além dessa, em comparação com as escolas individuais, o método mantém seus alunos disciplinados, habituados desde a primeira classe à ordem e à regra. Do ponto de vista pedagógico, a constituição de grupos disciplinares homogêneos faz com que as atividades propostas correspondam ao nível real de conhecimento dos alunos. A crítica centra-se na incompetência dos monitores, na maioria das vezes incapazes de fornecer explicações complementares, ou de adaptarse ao nível de compreensão de seus colegas; em um sistema empirico e prático, baseado em procedimentos mecânicos, portanto, desprovido de valor educativo; na inculcação de fórmulas e receitas; na transmissão de conhecimentos superficiais e sem valor, que não leva os alunos à reflexão e não desenvolve a inteligência. $O$ aluno é a grande vítima da mecânica do ensino monitorial/mútuo: está preso a um verdadeiro sistema militar, que o leva a agir somente mediante uma ordem e a submeter-se a um condicionamento destinado a torná-lo um cidadão dócil e obediente. Foucault considera o ensino mútuo uma máquina de quebrar os corpos e as inteligências ${ }^{11}$.

\section{A difusão do método lancasteriano na América Latina}

Para Caruso, a difusão do método lancasteriano se situa na história da internacionalização do saber pedagógico e dos modelos educativos, com vistas à oficialização de uma ordem escolar e de saberes pedagógicos

$\overline{11}$ Michel Foucault, Vigiar e Punir (Petrópolis: Vozes, 1977), 125-204. 
modernos, no século XIX ${ }^{12}$. A expansão mundial do método foi um processo de difusão sem precedentes na história da educação, sobretudo por sua rapidez e onipresença, mas também por ter sido o primeiro movimento de internacionalização, propriamente dito, no campo dos métodos e das didáticas. O sistema implantou-se rapidamente na Inglaterra, em numerosos países da Europa (Portugal, Espanha, França, Itália, Dinamarca, Bulgária, Holanda, Bélgica, para citar alguns), nos territórios africanos (Serra Leoa, África do Sul), na Austrália, nos Estados Unidos, no Canadá, nas Américas, no Brasil. A oficialização do método para as escolas das nascentes repúblicas implicava também uma decisão pelo tipo de sujeito republicano a formar, através da homogeneização do sistema escolar, para a produção de certas disposições ligadas à expansão do saber e da alfabetização ${ }^{13}$.

Ainda sob tutela da metrópole espanhola, alguns países da América Central implementam o método. Em Cuba, em 1814, artigos publicados no diário "El Cena" fazem alusão ao método, como solução para os problemas de falta de escolas e professores que o país passava no momento. Posteriormente, são fundadas escolas lancasterianas e uma Escola Normal em Havana, para difusão do método, com alunos provenientes de Porto Rico, Santo Domingo, Caracas $^{14}$.

Na Guatemala é traduzido o manual de Nyon - Manual practico del método de mutua enseñanza para escuelas de primeiras letras -, em 1819, mesmo ano de publicação na França. Depois da independência (1821), vários planos são elaborados recomendando a adoção do método, mas somente na década de 1830 que as iniciativas se fazem realidade, quando o país estabelece a escola laica, gratuita e obrigatória (1835). A primeira escola pelo método é de 1830 e uma escola normal lancasteriana é fundada em $1835^{15}$.

Desde 1819, no México encontram-se algumas escolas e professores adotando o método monitorial, mas o sistema se populariza depois da independência, com a fundação da associação filantrópica - Compañia Lancasteriana (1822) - com o fim de promover a educação primária entre

12 Marcelo Caruso, La oficialización del método lancasteriano. América Latina em el contexto del movimiento internacional por la educación mutua en: Anais do VI Congreso Iberoamericano de História de La Educación Iberoamericana: história de las ideias, actores e instituciones educativa (San Luis de Potosi) México, 2003), 1.

13 Caruso, La oficialización del método lancasteriano, 6.

14 Giner y Calderón España, El método de enseñanza mutua, 284.

15 Giner y Calderón España, El método de enseñanz̧a mutua, 287. 
as classes pobres ${ }^{16}$. A difusão foi tão rápida que em 1823 já contava com quase oitenta escolas privadas, totalizando 3.800 alunos atendidos. Nesse ano, também é criada a primeira escola normal lancasteriana. O prestígio e sucesso da Compañia Lancasteriana pode ser metido passados vinte anos, quando em 1842 o Governo entrega a responsabilidade da Direccion General de la Instrucción Primaria Publica, ampliando o número de escolas e de cidades que adotaram o sistema. A partir dos anos 1870, começa a decadência dessas escolas, que passam para o sistema público, culminando com a dissolução da associação filantrópica em $1890^{17}$.

$\mathrm{Na}$ América do Sul, a primeira escola lancasteriana encontra-se, provavelmente, no Uruguai em $1815^{18}$, por iniciativa do religioso Camilo Henriquez, que cria o Instituto Nacional, com o estabelecimento de escolas de primeiras letras pelo método monitorial. Esse fato, por si só, é uma contradição. A Igreja Católica foi grande opositora do sistema, especialmente na França, juntamente com segmentos conservadores, por considerá-lo fundado por estrangeiros, protestantes e formar sujeitos autômatos.

De 1817 a 1825, o Uruguai fez parte da Coroa Portuguesa - Reino Unido de Portugal, Brasil e Algarves, identificado como Província Cisplatina. Em 1817, o general Carlos Frederico Lecor, Barão de Laguna, de espírito progressista, toma a iniciativa de abrir uma escola lancasteriana. Outra escola é criada em Concepción, na província de Entre Rios, sob a proteção do comandante José Antonio Berdum e a regência de Solano Garcia, professor emigrado do Chile. Em 20 de abril de 1820, James Thomson passa por Montevidéu, com o intuito de apresentar suas idéias pedagógicas sobre o método. Estabelece contato com Dom Damásio Antonio Larrañaga, que juntamente com Lecor, funda a "Sociedade Lancasteriana", que inaugura em 3 de novembro de 1821 uma escola em Montevidéu. O regulamento da escola prescrevia que todos os dias o professor lesse, em voz alta, um capítulo da Sagrada Bíblia. Outras escolas são criadas, mas injunções administrativas, a propaganda contrária ao método (se ensinava aos meninos ensino militar com o fim de obrigá-los a serem soldados; não se ensinava doutrina cristã;

16 Sobre, ver Marcelo Caruso y Eugenia Roldán. El impacto de las nuevas sociabilidades. Sociedade civil, recursividad comunicativa y cambio educativo em la Hispanoamérica postcolonial. Revista Brasileira de História da Educação/SBHE, No. 26 (mai-ago 2011).

17 Giner y Calderón España, El método de enseñanza mutua, 291.

18 Sobre o método no Uruguai, ver Jesualdo Sosa, La escuela lancasteriana (Montevidéo: Letras, 1954); Elomar Tambara, A escola lancasteriana na província cisplatina en Anais do VII Encontro Sul-riograndense de pesquisadores em História da Educação (Pelotas: UFPel/ASPHE, 2001), 271-281; Ferreira, Fábio, O general Lecor e a escola Lancasteriana: método e instalação na Província Cisplatina (Tema Livre, n.13, 2002). 
que era impossível aos alunos aprender a ler e a escrever em quadros negros), a diminuição dos alunos, fez com que as escolas fossem fechadas em 1825, mas a vigência oficial do método permanece até $1840^{19}$.

Na Argentina ${ }^{20}$, temos notícia da aplicação do método em 1816, concomitante com Espanha. A tradução da obra de Lancaster para o espanhol - Origem y progressos del nuevo sitema de enseñanza mutua (1817), publicada em Buenos Aires, facilitou a circulação de suas idéias. Mas, a chegada em Buenos Aires, em 1818, de James Thomson, membro da British and Foreign School Society, com o objetivo de difundir, aplicar e expandir nas colônias de ultramar o sistema lancasteriano. Com o apoio de frades franciscanos, cria uma escola em 1819, inicialmente para meninos e, depois, para meninas. Em 1821 funda a Sociedade Lancasteriana e, em 1823, uma escola normal. O sistema se expandiu para outras províncias argentinas: Mendoza, San Juan.

Em 1821, Thomson segue para o Chile também contratado pelo Governo, onde cria uma escola na Universidad de San Felipe e outras escolas públicas (Valparaíso, Coquimbo). Os primeiros ensaios foram realizados no Instituto Nacional, que abre uma escola gratuita pelo método. Para ampliar a difusão do método, é contratado um professor da Inglaterra - Antonio Eaton, que chega em 1821 e se dedica a preparar os professores e ensinar inglês. O’Higgins, um dos expoentes da independência do Chile (1818), funda, em 17 de janeiro de 1822, a "Sociedade Lancasteriana". Em 1833, é retirada a gratuidade da escola lancasteriana do Instituto, pois os resultados foram considerados muitos fracos pela inadequada formação dos monitores. Permaneceu ainda algum tempo sendo adotado, principalmente nas escolas dominicais para adultos, promovidas por Andres Bello ${ }^{21}$.

Do Chile, Thompson parte para o Peru, em julho de 1822, sendo recebido por San Martín que lhe dá todo apoio oficial, sendo imediatamente criada uma Escola Normal no Colégio de Santo Tomás, para implementar o método. Na República da Nova Granada (Colômbia, Venezuela e Equador) ${ }^{22}$, a criação de escolas pelo método lancasteriano é patrocinada por Simón Bolívar,

19 Elomar Tambara, A escola lancasteriana na província cisplatina. Uma experiência brasileira? em: Anais do II Congresso Brasileiro de História da Educação/SBHE. (Natal: NAC-UFRN, 2002);

20 Sobre, ver Mariano Narondowski y Claudina López, El mejor de los métodos posibles: la introducción del método lancasteriano en Iberoamérica en el temprano siglo XIX, en $A$ Escola Elementar no século XIX. O método monitorial/mútuo Eds Maria Helena Camara Bastos y FARIA Filho, Luciano Mendes de Faria Filho (Passo Fundo: Ed.UPF, 1999), 45-72.

21 O sistema lancasteriano no Chile e em outros países da América do Sul foi objeto de estudo de Domingo Amunátegui Solar em 1895. Sobre, ver José Rojas Flores, Historia de la infancia en el Chile Republicano (1810-2010) (Santiago: Junta Nacional de Jardines Infantiles, 2010).

22 Sobre, ver Caruso, La oficialización del método lancasteriano (2003). 
que dava especial atenção à educação popular, fruto combinado das idéias do Iluminismo e dos ideais revolucionários e filantrópicos de sua época ${ }^{23}$. Por sua iniciativa, cria uma "Camara de Educação" (1821), a qual devia se encarregar da educação de todas as crianças de zero a 12 anos, idade limite da escolaridade obrigatória, e também da educação das mães. Entre suas atividades, objetivava publicar, em castelhano, as melhores obras estrangeiras sobre educação; enviar professores em missões pedagógicas; contratar professores com domínio do método; criar escolas normais em Bogotá, Caracas e Quito ${ }^{24}$. Simón Bolívar encarrega o vice-presidente Francisco de Paula Santander de elaborar a legislação para implantação de escolas normais (26 de janeiro de 1822) ${ }^{25}$. Para a formação docente, é publicado o "Manual del sistema de enseñanza mutua aplicado a las escuelas primarias de los niños" (Bogotá, 1826), como iniciativa da Comisión Central Del Instituto de Borough de la Sociedad para las Escuelas Británicas y Extranjeras, a qual promovia a obra de Lancaster. Em 1845, o Governo ordena a impressão do "Manual de ensenñanza mutua para las escuelas de primeiras letras", de autoria de José Maria Triana, diretor da Escola Normal ${ }^{26}$.

Em 1818, o próprio Lancaster emigra para a América, devido a problemas com Bell e com o clero anglicano, estabelecendo-se em Caracas/Venezuela, de 1824 a 1827. Com o apoio de Simón Bolívar, dirige a primeira Escola Normal, em Caracas, cuja aspiração era difundir seu sistema por toda Gran Colômbia. No entanto, vários fatores contribuíram para a inviabilização do seu projeto: o idioma, a falta de locais adequados para estabelecer escolas para um grande número de alunos, a falta de materiais necessários para por em prática o método, e, por fim, sua enfermidade. Em 1829, vai para o Canadá, onde recebe subvenção do governo para difundir o método. Regressa ao E. U. A., vindo a falecer em 1838. No período que vai de 1821 a 1844, o Estado oficializa o sistema lancasteriano, mas o método continua a ser propagado e permanece vigente nos planos de estudo da Colômbia até meados, e em alguns lugares até fins, do século XIX, solucionando com ele a escassez de mestres e como recurso a brindar a instrução das primeiras letras para grande quantidade de estudantes ${ }^{27}$.

23 Giner y Calderón España, El método de enseñanza mutua, 296.

24 José Pascual Mora-Garcia, Aproximación filosófica a la nueva ley orgánica de educación: aciertos, silencios e vacíos. DIKAIOSYNE No. 23. (Julio-diciembre, 2009), 120.

25 Francisco de Paula Santander foi um dos principais ideólogos e responsáveis pela implantação do programa educativo. Sobre, ver Mora-García, Aproximación filosófica a la nueva ley orgánica de educación, 119.

26 Olga Zuluaga, Entre Lancaster y Pestalozzi: los manuales para la formación de maestros em Colômbia (1822-1868), en Anais do VI Congreso Iberoamericano de História de La Educacion Iberoamericana: história de las idéias, actores e instituciones educativa. (San Luis de Potosi/México, 2003).

27 Giner y Calderón España, El método de enseñanza mutua, 299. 
Diferentemente das colônias espanholas, o Brasil, em 1808, passa a ser sede da Coroa Portuguesa e uma série de medidas são tomadas no campo cultural e educacional. A instrução pública do ensino de primeiras letras, no entanto, não merece a atenção das autoridades. D. João VI incumbe o ministro Antônio de Araújo de estudar um "método, para dar aos institutos, às academias, a unidade necessária às escolas, a unidade necessária à formação de um grande povo". O Conde de Barca preocupa-se com a educação como problema do Estado e partilha do interesse das esferas políticas pelo sistema lancasteriano de educação, tendo lido as obras Travail sur l'éducation publique, de Mirabeau o Velho, e Improvements in education as it respects the industrious classes of the community, de J. Lancaster ${ }^{28}$.

O Correio Brasiliense (Londres), de abril a outubro de 1816, publica uma série de artigos sobre o método Lancaster que apresenta "um resumo histórico do princípio e progressos deste novo sistema de educação na Inglaterra; e explica em que consiste a vantagem destas instituições" ${ }^{29}$. Os artigos atuam como propaganda do método ao leitor brasileiro - "os sistemas de educação, que se inventaram na Inglaterra e tem obtido melhoramentos sucessivos, são destinados a preencher aquelas vistas; e por isso que intentamos propôlos como exemplo digno de imitar-se em Portugal e no Brasil, aonde a necessidade da educação elementar é tão manifesta que julgamos não carecer de demonstração" 30 .

Uma particularidade na implantação do sistema lancasteriano no Brasil é a iniciativa de franceses, residentes no Brasil, com a aplicação em negros escravos, como dispositivo de libertação:

Eu me ocupei de comunicar, no Brasil, os beneficios do ensino mútuo, fazendo principalmente a aplicação em jovens negros, de um e outro sexo, que são trazidos da costa da África, nos quais as faculdades morais são praticamente nulas. Eu já obtive resultados que prometem ser venturosos. As idéias se fixam e o amor-próprio se desenvolve pelo desejo de ser monitor, por mais difícil que seja formá-los. Até o momento presente, faço todos os quadros à mão e os componho eu mesmo. Diante das formalidades da alfândega e a censura sobre os objetos impressos, eu não pude superar as dificuldades para a introdução dos materiais, necessários à aplicação do método, a não ser que a sociedade pudesse me fazer chegar um ou dois exemplares de todos os quadros, e de tudo que faz publicar, principalmente o que é relativo à instrução das meninas, parte que eu pouco segui e que é muito importante neste país. Seria

\footnotetext{
28 María Beatriz Nizza da Silva, Cultura e Sociedade no Rio de Janeiro (1808-1821) (São Paulo: Nacional; Brasília: INL. 1977), 177-78.

29 María Helena Camara Bastos, A Educação Elementar e o método lancaster no Correio Braziliense (1816). Revista História da Educação. ASPHE/UFPel, V. 9, No. 17 (abr. 2005), 193-222.

30 Correio Braziliense, abril de 1816, 346-350.
} 
necessário que essa remessa se realizasse por intermédio do Ministério e fosse dirigida ao Cônsul da França, ao qual faria o reembolso das despesas e dos fretes. A sorte dos negros é tão desgraçada que concorrer para amenizá-la entramos, sem dúvida, nos aspectos filantrópicos da sociedade. Pela instrução os negros conseguem reunir os fundos necessários para comprar a sua liberdade e a de seus filhos. Não tenho mais nada a acrescentar à essa observação. Assim que meus ensaios tiverem tido aprovação do governo, enviarei cópia do processo verbal à Sociedade e informá-la-ei dos resultados dos mens esforços, que terão vencido, e o espero, todos os obstáculos ${ }^{31}$.

Em agosto de 1819, o Journal d'éducation informa outra iniciativa.

De um francês fundou uma escola no Brasil, em favor dos jovens negros de ambos os sexos, vindos da costa da África, solicitou instruções e conselhos à Sociedade. Este desejo foi acolbido com entusiasmo, e enviamos ao Rio de Janeiro os modelos, livros, quadros, etc. Pela instrução, os infelizes negros conseguiram comprar a sua liberdade e de seus filhos ${ }^{32}$.

Em agosto de 1820, o periódico publica outra carta do Conde Scey, datada de 4 de junho, em que informa que "o Conde de Gestas seguiu o meu exemplo em sua terra, e todos os seus escravos receberam os conhecimentos elementares sobre a língua francesa e portuguesa, educação religiosa, e ganhou muito com isso" (Journal d'éducation. Paris, ano V, n.XI, aôut 1820, 313). Essa carta evidencia a divulgação do método entre os franceses estabelecidos no Brasil e o conteúdo do ensino ministrado aos negros.

Essas primeiras iniciativas particulares foram também acompanhadas de medidas governamentais, tais como o Decreto de 3 de julho de 1820, que "concede a João Batista de Queiroz uma pensão anual, para ir à Inglaterra aprender o sistema lancasteriano" ${ }^{33}$ Essa medida evidencia tanto o interesse oficial na implantação do método mútuo, como a busca na Inglaterra do referencial necessário à formação de docentes. A partir de 1820, o Estado gradativamente implanta o método de forma oficial. Assim, em Decisão do Reino no 83, de 24 de julho de 1822, "fica a cargo da Repartição dos Negócios da Guerra a Escola do Ensino Mútuo desta cidade (Rio de Janeiro)”.

A independência do Brasil, em 1822, não altera o quadro da instrução pública e o interesse na implantação do sistema monitorial/mútuo. A fala do Imperador Dom Pedro I, na inauguração da Assembléia Constituinte, em 3

\footnotetext{
31 Journal d'éducation, ano IV, N.X, juillet (Paris: 1819).

32 Journal d'éducation, ano IV, N. XI, aôut (Paris: 1819), 230.

33 Josephina Chaia, A educação brasileira. Índice sistemático da legislação (1808-1889) (Marília: FFCL, 1963), 34.
} 
de maio de 1823, denota essa intenção: "conhecendo a vantagem do ensino mútuo também fiz abrir uma escola pelo método lancasteriano". O Decreto de $1^{\circ}$ de março de 1823 , "cria uma escola de primeiras letras, pelo método do Ensino Mútuo, para instrução das corporações militares", acrescenta que "sendo em benefício, não somente dos militares do Exercito, mas de todas as classes dos meus súditos que queiram aproveitar-se de tão vantajoso estabelecimento". É interessante observar a forma de recrutamento dos docentes adotada pelo Governo, seguindo a tendência de criação, controle e administração das escolas de Ensino Mútuo pela Repartição da Guerra - os militares foram considerados mais adequados para atuarem como lentes nas escolas/aulas de primeiras letras pelo método lancasteriano. Essa preferência evidencia uma aproximação entre a disciplina e a ordem exigida e adotada pelo método, nas duas instituições - militar e escolar ${ }^{34}$. A origem oficial das escolas de ensino mútuo vinculada à repartição da Guerra parece ter seguido orientação já dada na Metrópole.

O Decreto das Escolas de Primeiras Letras, de 15 de outubro de 1827, primeira lei sobre a Instrução Pública Nacional do Império do Brasil, propõe a criação de escolas primárias com a adoção do método lancasteriano. Esse decreto determina oficialmente o método pedagógico a ser adotado em todas as escolas de primeiras letras do País. Aos professores que não tivessem a necessária preparação neste método, o decreto previa a sua instrução a curto prazo e à custa do seu ordenado nas escolas das capitais.

\begin{abstract}
As escolas serão de Ensino Mútuo nas capitais das provincias; e o serão também nas cidades, vilas e lugares populosos delas em que for possivel estabelecerem-se. Para as escolas de ensino mútuo se aplicarão os edificios, que houver com suficiência nos lugares delas, arranjando-se com os utensílios necessários à custa da Fazenda Pública. Os professores que não tiverem a necessária instrução deste Ensino, irão instruir-se a curto prazo e à custa do seu ordenado nas escolas das capitais. Os professores ensinarão a ler, escrever, as quatro operações de aritmética, prática de quebrados, decimais e proporções, as noções mais gerais de geometria prática, a gramática da língua nacional, os princípios de moral cristã e de doutrina da religião católica e apostólica romana, proporcionadas à compreensão dos meninos; preferindo para o ensino da leitura a Constituição do Império e História do Brasil. (...) ensinarão também as prendas que servem à economia doméstica. (...) Os castigos serão aplicados pelo método de Lancaster.
\end{abstract}

34 Esse sistema de recrutamento de professores nos quadros militares parece ter perdurado por alguns anos. Somente, em 12 de maio de 1837, a Decisão No. 166 do Império, torna incompatível as funções de militar e professor público, quando declara que "um militar não pode ser admitido a concurso de preenchimento de cadeira de professor público”. Bastos, O ensino mútuo no Brasil, 106. 
Nas discussões relativas ao projeto de lei para a Instrução Pública Primária, são registradas falas que tanto questionam o método - "que se dê ao mestre o arbítrio de ensinar pelo sistema que julgar melhor e não se deve obrigá-lo ao método de Lancaster; a escola de ensino mútuo é diferente das outras? pergunta o Sr. Hollanda Cavalcanti"; como fazem a sua defesa - "de tudo, que tenho lido, não encontrei um método como o de Lancaster, pode ser mau mas não há melhor; ele bebeu essa grande doutrina na Índia e é de lá que tirou esse grande método de ensinar, não sabe como se pode dizer que o método de ensino mútuo não é bom, e que possam haver argumentos que mostrem o contrário; diz o Sr. Cunha Mattos" ${ }^{\prime 35}$. Essas falas serão recorrentes a partir de 1827, no período de implantação e generalização do método nas províncias, que esbarrou em uma série de obstáculos: falta de adequados prédios escolares e de materiais necessários a adoção do método mútuo; descontentamento dos mestres, falta de proteção dos poderes públicos e de recompensa pecuniária; formação adequada dos professores.

Visando sanar, em parte, o problema de formação de professores é criada a primeira Escola Normal do Brasil (1835-1851) ${ }^{36}$, na capital da Província do Rio de Janeiro - Niterói. Sua criação fez parte de um projeto maior do grupo conservador fluminense que assume a direção da Província a partir da promulgação do Ato Adicional de 1834. Nesta perspectiva, insere-se outra iniciativa do Presidente Paulino Soares de Souza, que determina, em 1839, a tradução e impressão da obra do Barão De Gérando, intitulada “Curso Normal para Professores de Primeiras Letras ou Direcões relativas à Educação Physica, Moral e Intellectual nas Escolas Primárias", editada na França em 1832.

Em 1838, o Ministro Bernardo de Vasconcelos, analisa em seu relatório os percalços por que o método monitorial/mútuo não correspondia à expectativa dos seus propagandistas no Brasil e na Europa:

Todavia os resultados do sistema lancasteriano não correspondem à expectação pública quer no tempo, quer na perfeição. E não é só no nosso país que isto se observa: na Europa, onde bá abundância de professores muito habilitados e facilidade de se encontrar todos os requisitos à rigorosa execução deste sistema, acontece o mesmo como se vê das recentes publicaçoes de Mr. Cousin que examinon os estabelecimentos de instrução da Prússia e na Holanda. É sabido que o método lancasteriano limita-se a uma instrução grosseira por assim dizer, própria para as

35 Primitivo Moacyr, A Instrução e o Império. Subsídios para a História da Educação no Brasil (1823-1835). (São Paulo: Cia. Ed. Nacional, 1936), 181.

36 Sobre, ver Heloísa de O.S. Villela, O ensino mútuo na origem da primeira escola normal do Brasil en A Escola Elementar no século XIX, eds Bastos y Faria Filho, 145-176. 
últimas classes da sociedade e não se estende ao apuro e à delicadez̧a, à correção, ao cálculo que, na gramática, na religião, e nos outros conbecimentos a civilização de hoje exige na instrução primária de todas as classes superiores àquelas as quais pelo inverso do que acontece na Europa abrangem a mesma população.

O que se percebe em distintos discursos é uma crítica intransigente ao método, centrada nas dificuldades de implantação, na falta de prédios escolares adequados ou ao princípio ativo do método: uma máquina, sem nenhum princípio de vida. O período de adoção do ensino mútuo no Brasil não é possível de ser delimitado com precisão. Legalmente, poderíamos dizer que a reforma Couto Ferraz (Decreto n. 1331, de 17 de fevereiro de 1854, que regulamenta a instrução primária e secundária do Município da Corte), no artigo 73, estabelece que o método de ensino a ser adotada nas escolas em geral será o simultâneo. A partir desse regulamento, encontra-se nas escolas a presença tanto do método simultâneo, do método mútuo, e de um sincretismo de ambos, denominado método misto.

\section{CONSIDERAÇÕES}

A oficialização do sistema lancasteriano na América Latina se dá em um momento marcado por forte idealização da educação, pela crença ilimitada no poder civilizatório da instrução. Para Lesage, "o método lancasteriano, pelos debates que provocou, marca, profundamente, a didática do século XIX. Graças a ele, a questão escolar tornar-se-á, ao menos em nível institucional, uma questão nacional, ampliando as perspectivas de desenvolvimento e de generalização do ensino elementar" 37.

Na América espanhola a implantação oficial do método pelas nascentes repúblicas foi a solução buscada para a ampliação da escolarização das classes populares, mas também para a proliferação dos ideais liberais, através da ação das sociedades filantrópicas criadas para sua difusão. No entanto, a expansão não se estendeu por muito tempo, decorrente da falta de recursos econômicos, por problemas do próprio método (prédios escolares, materiais didáticos, etc.), por reações dos professores, pela rotatividade dos monitores ${ }^{38}$.

No Brasil, ao contrário, para Xavier "a adoção do método mútuo expressava exatamente a desmotivação do Estado agroexportador e

37 Lesage, La pedagogie dans les écoles mutuelles, 23.

38 Giner y Calderón España, El método de enseñanz̧a mutua, 299.

Rev. hist.edu.latinoam - Vol. 14 No. 18, enero-junio 2012 - ISSN: 0122-7238 - pp. 75 - 92 
escravocrata em garantir as condições mínimas para o funcionamento da escola pública, ou seja, a formação e remuneração adequada de professores. Dessa forma, acabou se transformando num fator a mais para a fragilização, em termos de qualidade, do ensino público elementar no período" ${ }^{39}$.

Da implantação do método podemos destacar alguns dispositivos importantes que permaneceram nos sistemas de ensino: a expansão lenta e gradativa da escolarização elementar às classes populares, a sistematização e seriação das disciplinas, o uso de variados materiais didáticos em sala de aula (quadros murais, livros, cadernos, caderno de freqüência, caderno de matrícula, etc.), o calendário escolar, a ordem e a disciplina.

A adoção do método lancasteriano nas Américas e Brasil esteve afinada com o movimento de internacionalização de saberes pedagógico e modelos educativos, na primeira metade do século XIX. No entanto, não podemos afirmar que houve homogeneização de uma ideologia educativa, tendo em vista as inúmeras variações entre os projetos de nacionalização do método e de construção de identidades nacionais.

\section{FONTES}

Brasil. Decreto n. 1331 A, de 17 de fevereiro de 1854. Aprova o regulamento para a reforma do ensino primário e secundário do Município da Corte. en: Coleção das Leis do Império do Brasil. Rio de Janeiro: Tipografia Nacional, s/d. Tomo 17, parte $2^{\circ}$, seção $12^{a}$.

\section{REFERÊNCIAS}

Amunategui, Solar Domingo, El sistema Lancaster en Chile $i$ en otros países de Sud-América. Santiago/Chile: Imprenta Cervantes, 1895.

Bastos, Maria Helena Camara, "O ensino mútuo no Brasil (1808-1827)", em A Escola Elementar no século XIX . Maria Helena Camara Bastos y Faria Filho, Luciano Mendes. O método monitorial/mútuo. Passo Fundo: Ed.UPF, 1999.

Bastos, Maria Helena Camara, A formação de professores para o ensino mútuo no Brasil: O "Curso Normal para professores de primeiras letras" do barão de Gérando (1839), en $A$ Escola Elementar no século XIX. O método monitorial/mútuo, Bastos, Maria Helena Camara y Faria Filho, Luciano Mendes. Passo Fundo: Ed.UPF, 1999.

Bastos, Maria Helena Camara, "Esclaves, Militaires et Libéraux: les chemins de l'enseignement mutuel au Brésil (1808-1854)". Paedagogica Histórica. Vol. 41, Nº 6, December (2005): 677-697.

Braziliense (1816), Revista História da Educação. ASPHE/Pelotas, V. 9, No. 17 (2005): 193-222.

39 María Elisabete Xavier, História da Educação: A escola no Brasil (São Paulo: FTD, 1994), 65. 
Cardoso, Tereza Maria R. Fachada L. Abrindo um novo caminho: o ensino mútuo na escola pública do Río de Janeiro (1823-1840), en A Escola Elementar no século XIX. O método monitorial/mútuo. Bastos, María Helena Camara y Faria Filho, Luciano Mendes, Passo Fundo: Ed.UPF, 1999.

Caruso, Marcelo. La oficialización del método lancasteriano. América Latina em el contexto del movimiento internacional por la educación mutua, en Anais do VI Congreso Iberoamericano de História de La Educacion Iberoamericana: história de las idéias, actores e instituciones educativa. San Luis de Potosi/México, 2003.

Caruso, Marcelo y Roldán, Eugenia. El impacto de las nuevas sociabilidades. Sociedade civil, recursividad comunicativa y cambio educativo em la Hispanoamérica postcolonial. Revista Brasileira de História da Educação/SBHE, No. 26, mai-ago 2011.

Chaia, Josephina. A educação brasileira. Índice sistemático da legislação (1808-1889). Marília: FFCL, 1963.

Fernandes, Rogério (1999): A difusão do ensino mútuo em Portugal no começo do século XIX, en Bastos, Maria Helena Camara y Faria Filho, Luciano Mendes. A Escola Elementar no século XIX. O método monitorial/mútuo. Passo Fundo: Ed.UPF, 1999.

Flores, José Rojas. Historia de la infancia en el Chile Republicano (1810-2010). Santiago: Junta Nacional de Jardines Infantiles, 2010.

Foucault, Michel. Vigiar e Punir. Petrópolis: Vozes, 1997.

Giner, María Isabel Cortis, y Calderón España, María Consolación. El método de enseñanza mutua. Su difusión en la América Colonial Española, História da Educação. Salamanca, V. XIVXV, (1995)-96, 279-300.

Moacyr, Primitivo. A Instrução e o Império. Subsídios para a História da Educação no Brasil (18231835). São Paulo: Cía. Ed. Nacional, 1936.

Narodowski, Mariano, y López, Caludina. El mejor de los métodos posibles: la introducción del método lancasteriano en Iberoamérica en el temprano siglo XIX, en Bastos, Maria Helena Camara y Faria Filho, Luciano Mendes. A Escola Elementar no século XIX. O método monitorial/mútuo. Passo Fundo: Ed. UPF, 1999.

Peters, Heinz. El sistema educativo paraguayo desde 1811 hastas 1865. Paraguay: Instituto Cultural Paraguayo-Alemán, 1996.

Querrien, Anne. L'école mutuelle, une pédagogie trop efficace? Paris: Empencheur de Penser en Rond, 2005.

Sosa, Jesualdo. La escuela lancasteriana. Montevidéo, Letras, 1954.

Tambara, Elomar. A escola lancasteriana na província cisplatina, em Anais do VII Encontro Sul-rio-grandense de pesquisadores em História da Educação. Pelotas: UFPel/ASPHE, 2001.

Villela, Heloísa de O.S. “A primeira Escola Normal do Brasil. Uma contribuição à História da Formação de Professores”. (Dissertação de Mestrado em educação na Universidade Federal Fluminense, 1990).

Villela, Heloísa de O.S. O ensino mútuo na origem da primeira escola normal do Brasil, en Bastos, Maria Helena Camara y Faria Filho, Luciano Mendes. A Escola Elementar no século XIX. O método monitorial/mútuo. Passo Fundo: Ed. UPF, 1999.

Vincent, Guy. L'école primaire française. Etude sociologique. Lyon: Pulyon, 1980.

Xavier, Maria Eluizabete et alii. História da Educação: A escola no Brasil. São Paulo: FTD, 1994. 
Zélis, Guy. L'École Primaire en Belgique, depuis Moyen Âge. Belgique: Galerie GGER, 1986-87.

Zuluaga, Olga. (2003): Entre Lancaster y Pestalozzi: los manuales para la formación de maestros em Colômbia (1822-1868), en: Anais do VI Congreso Iberoamericano de História de La Educacion Iberoamericana: história de las idéias, actores e instituciones educativa. San Luis de Potosi/

México, 2003.

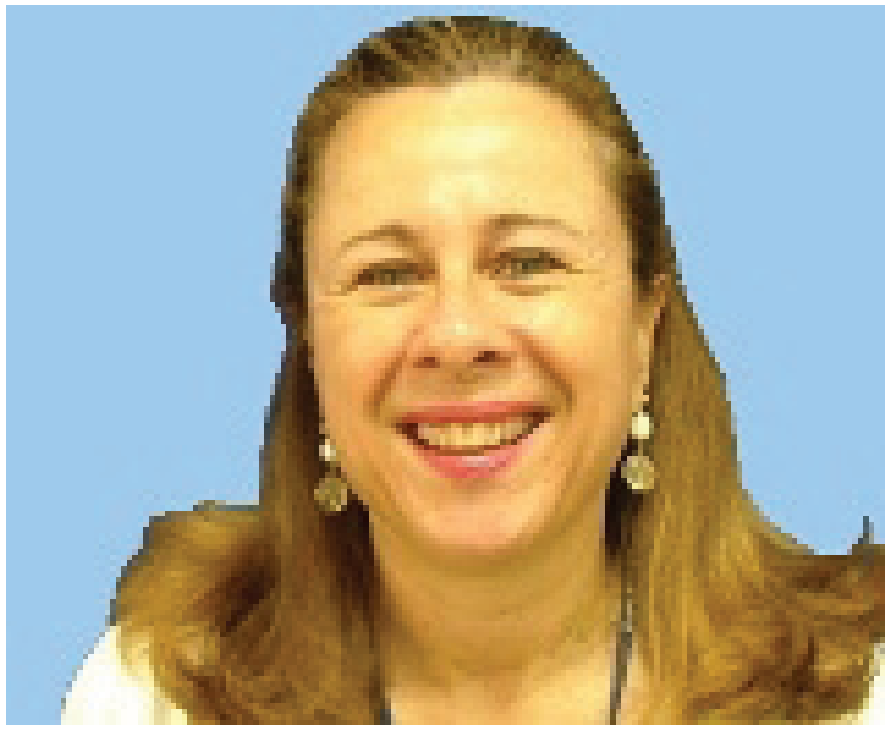

Archivo Personal María Helena Camara Bastos

Camara Bastos, María Helena. "Instrução pública e independências na América Espanhola e Brasil: experiências lancasterianas no século XIX". Revista Historia de la Educación Latinoamericana Vol. 14 No. 18, (2012): pp. 75 - 92. 